\title{
Sexually transmitted diseases
}

\section{Extract from the Annual Report of the Chief Medical Officer of the Department of Health and Social Security for the year 1974}

In view of the fact that clinics for the sexually transmitted diseases (STDs) also deal with a considerable number of other genito-urinary conditions, a trend has developed to change the name of the specialty from the narrower and more emotive title venereology to genito-urinary medicine. This term, which was recommended by the Royal College of Physicians of London, has now been accepted by the Department. The change is considered to be to the advantage of patients and of the general practitioners referring them to the clinics, and it is hoped that recruitment to this shortage specialty will also be improved.

It has become clear in 1974 that the struggle to contain the venereal and other sexually transmitted diseases must be intensified. Early syphilis figures continue to rise; mainly owing to an increase in homosexual male cases, though there is some evidence that this increase is beginning to spill over into the female population, presumably due to spread via bisexual males. The gonorrhoea figures have shown a slight decrease but have not changed significantly; in fact, during the last 5 years, they have varied by less than 10 per cent. The numbers of cases of nonspecific genital infection continue their upward trend and increases have also been recorded in most of the other sexually transmitted diseases.

There are therefore grounds for concern but the situation must be viewed against the facts that the incidence rates for syphilis and gonorrhoea in England (and in the rest of the United Kingdom) are among the lowest in the world, and that the clinic services continue to be strengthened by improvements in premises and increases in medical, nursing, and ancillary staffing. The rate in this country for early infectious syphilis was 3.3 per 100,000 population in 1973 and 3.5 in 1974 , as compared with 12.1 and 11.9 respectively in the United States of America; and the rates for gonorrhoea in 1973 and 1974 were $126 \cdot 1$ and $124 \cdot 9$, as compared with $392 \cdot 2$ and $420 \cdot 1$ respectively in the USA.

'On the State of the Public Health'. Report of the Department of Health and Social Security for the year 1974, pp. 77 to 82 . HMSO, London

\section{Syphilis}

Early syphilis comprises the primary, secondary, and early latent stages. In 1974 there were 2,278 cases, 1,906 in males $(1,802$ in 1973) and 372 in females (331 in 1973) giving a combined incidence of 4.90 per 100,000 population as compared with 4.59 in 1973 (Table I). The male:female ratio in 1974 was $5 \cdot 1: 1$ as compared with $5 \cdot 4: 1$ in 1973 . If the latent cases are excluded, then the total of early infectious syphilis for 1974 was 1,648 cases, 1,395 in men and 253 in women, giving a combined incidence of 3.54 per 100,000 population as compared with 3.26 in 1973. The male:female ratio in 1974 was $5 \cdot 5: 1$ as compared with 6.0:1 in 1973 .

Information was obtained from the clinics on the numbers of cases of early infectious syphilis believed to have been contracted $(a)$ in the United Kingdom and $(b)$ abroad. The totals were $(a)$ 1,323 (80.3 per cent.) and (b) 243 (14.7 per cent.) respectively with $82(5.0$ per cent.) not known. In $1973,15 \cdot 8$ per cent. of infections were contracted abroad.

The age breakdown for cases of early infectious syphilis per 100,000 population is shown in Table $I$. The highest incidence rate is still in the 20 to 24-year age group in men, but in the 18 to 19 -year age group in women.

During 1974, steps were taken to obtain the attendance at a clinic of 1,828 contacts of cases of syphilis. As a result, 1,353 contacts, 904 males and 449 females, attended; of these 313 males and 172 females were found to have syphilis.

Cases of late syphilis (all forms) rose from 1,171 in 1973 to 1,200 in 1974, an incidence of 2.58 per 100,000 population. In 1974 there were 90 cases of cardiovascular syphilis (64 in men and 26 in women), compared with 76 in 1973. The 1974 figures for neurosyphilis were 114 ( 88 in men and 26 in women), compared with 144 in 1973 . There were 996 cases at all other late and latent stages, 670 men and 326 women. Unpublished provisional figures for 1974 (Office of Population, Censuses and Surveys) recorded deaths in nine men and five women with general paralysis of the insane, in seven men and eight 
women with tabes dorsalis, and in twelve men and 23 women with syphilitic aortic aneurysm.

The number of new cases of treponemal diseases presumed to be non-syphilitic showed an unexplained rise. In 1974 there were 1,066 cases reported from the clinics, 708 in men and 358 in women, giving an incidence of 2.29 per 100,000 population, compared with 1.86 in 1973 (Table II) when the number was 864 (549 in men and 315 in women).

The total figure for all congenital infections was 163 (56 in males and 107 in females) as compared with 163 (61 in males and 102 in females) in 1973, an incidence of 0.35 per 100,000 population, the same as in 1973 (Table I).

Serological tests for treponemal disease in pregnancy carried out at five regional centres in 1974 totalled 168,167 , of which 71 were positive $(0.042$ per cent); in 1973, 82 out of 146,059 were positive (0.056 per cent.).

\section{Gonorrhoea}

The total number of new cases was 58,139, a decrease of 0.9 per cent.) as compared with 1973. New cases in males numbered $37,361(1.3$ per cent. less than in 1973) and 20,778 in females $(0 \cdot 2$ per cent. less than in 1973). The postpubertal figures were 58,071, 37,337 in men and 20,734 in women; the incidence per 100,000 population is given in Table I where details of age incidence rates can also be found. The male:female case ratio was $1 \cdot 8: 1$, the same as in 1973. The prepubertal cases numbered 68 , comprising 26 of vulvo-vaginitis, eight of urethritis, and 34 of gonococcal ophthalmia; the figures for 1973 were 31,2 , and 55 respectively.

Infections under 16 years of age occurred in 118 boys and 460 girls in 1974 as compared with 151 boys and 458 girls in 1973. The number of cases in boys aged 16 to 19 was 4,564 , compared with 4,670 in 1973, and the number of girls of that age 6,543 , compared with 6,629 in 1973.

Information was obtained from the clinics on the numbers of postpubertal cases of gonorrhoea believed to have been contracted abroad. In 1974 the figures were $1,711,3.0$ per cent. of the total of 58,071 ; in 1973 the equivalent percentage was 3.2 per cent.

In 1974 steps were taken to obtain the attendance at a clinic of 36,943 contacts of cases of gonorrhoea. As a result, 23,529 contacts, 8,263 males and 15,266 females, attended; of these, 4,763 males and 11,316 females were found to have gonorrhoea.

\section{Chancroid}

This disease remains a rarity in England. There were 43 new cases reported in 1974, 38 in males and five in females, compared with 36 in 1973, 34 in males and two in females. This gives an incidence of 0.09 per cent per 100,000 population compared with 0.08 in 1973 (Table I).

\section{Other sexually transmitted diseases}

The figures reported in 1974 were as follows, the 1973 figures being added in parentheses for comparison (for incidence rates per 100,000 population see Table II):

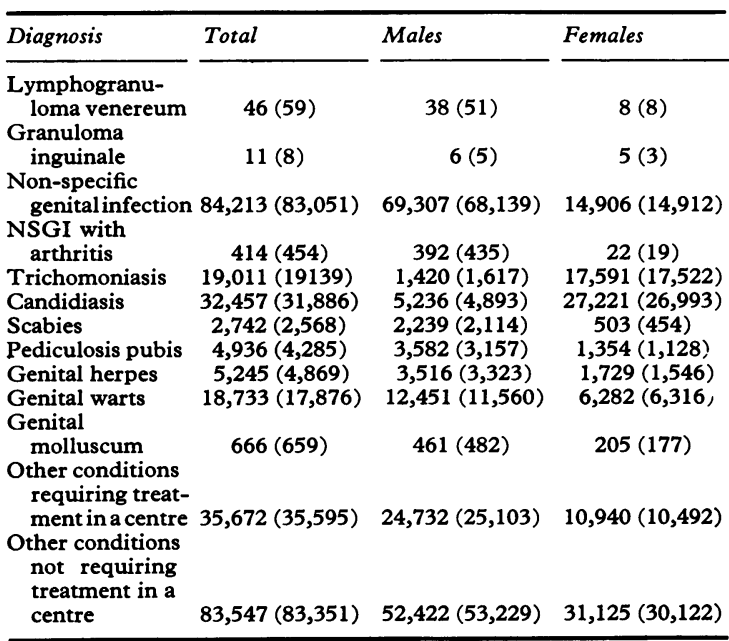

A particular point of interest is that the increase in cases of non-specific genital infection (NSGI) in men was relatively small compared with that in previous years. There was a marked fall in the number of cases of non-specific genital infection with arthritis in men.

\section{The present position}

The new Design Guide (Department of Health and Social Security, 1974) was distributed to Regional Health Authorities and to Boards of Governors in September, 1974. This document should help those who are planning new clinics in District General Hospitals. A University Chair in Genito-urinary Medicine has now been agreed by the Academic Board of the Middlesex Hospital and an appeal has been launched to raise the necessary capital to endow an academic department there. A further number of new appointments to Senior Registrar and Registrar posts have been made this year in this shortage speciality.

Training courses approved by the Joint Board of Clinical Nursing Studies continue in London, Sheffield, and Birmingham.

A meeting at the Department discussed commissioned research on sexually transmitted diseases and assessed the work already receiving support from the Medical Research Council. It was agreed that disease control depended on reliable information 
\begin{tabular}{l}
\multirow{1}{1}{} \\
0 \\
0 \\
0
\end{tabular}

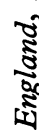

政

.

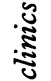

ర్

รั้

|

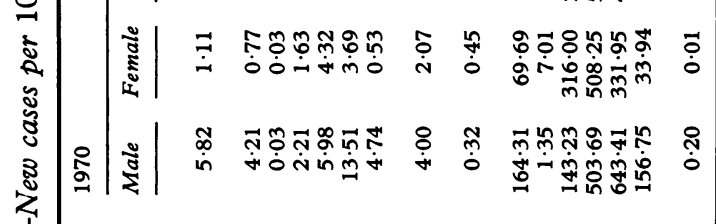

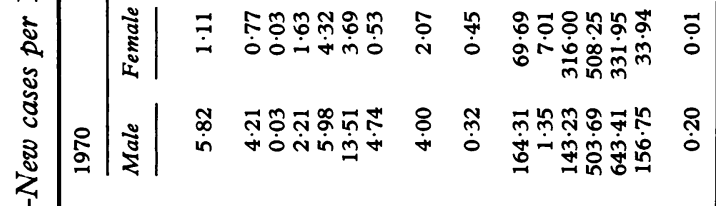
荡|

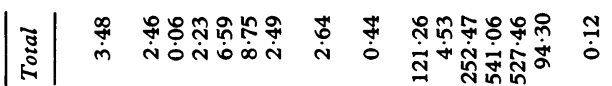

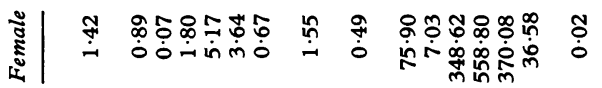
至|

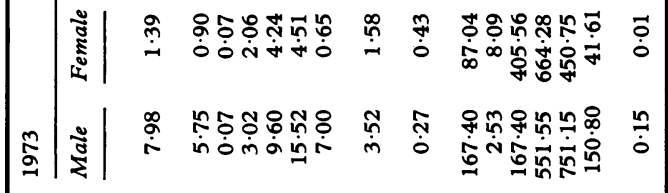
|

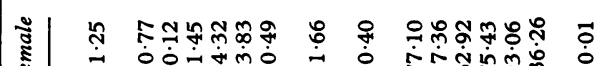

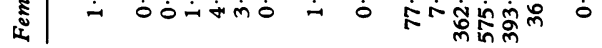
芯|

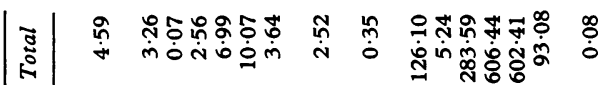

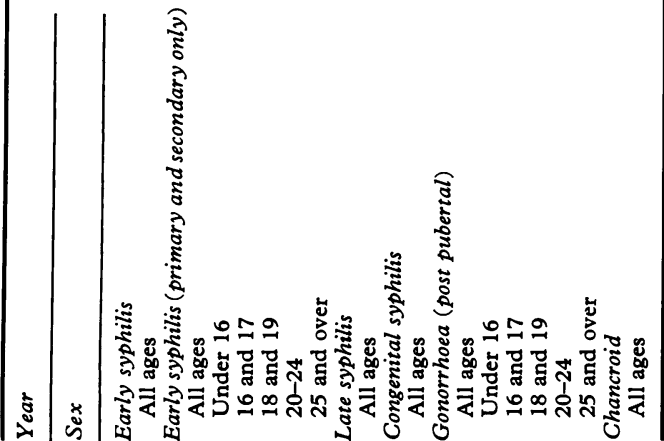

$\frac{\sqrt{3}}{3}$

ช

ฐँ

๙ู

गे

ชี

gั

$\approx$

ช

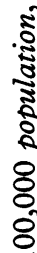

ฐ

๖

క

I

ปี

ธิ

ปั้

จ

๖ั

:

:

)

ปู

ธัँ

ज ซี

떵

茴战

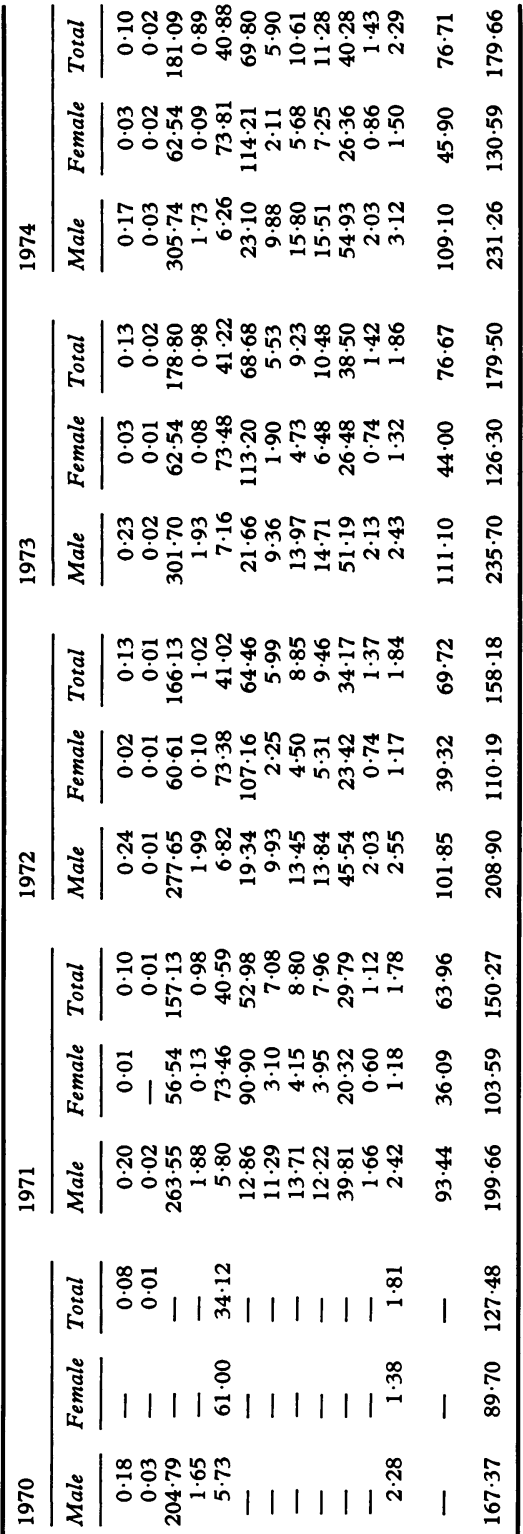

을 
about the extent and nature of the problems. Epidemiological studies to investigate social and behavioural factors involved in disease transmission should receive strong support. Investigations likely to lead to advances in the field of immunization should be encouraged in relation to both gonorrhoea and syphilis. More information on the causation of nonspecific genital infection was required and systemic therapy for candidiasis and genital virus infections needed development. Overseas visits by British researchers had proved of considerable benefit.

The new project sponsored by the Health Education Council (mentioned in the report for 1973) is progressing in a number of clinics in London and the provinces. The project is attempting to formulate the role of staff engaged in tracing the contacts of patients offering from STDs. The basic function is to obtain information about sex contacts at interviews of patients mainly with early infectious syphilis and gonorrhoea. As a result of the interview it is hoped that sex contacts will attend a clinic, although in addition the contact may have to be visited. Other important functions include explaining to patients how to avoid re-infection, stressing the importance of completing treatment and surveillance, and considering any social or emotional problems that may need specialized attention. Those who default before completing treatment must also be sought. In this research project a confidential information system is being evolved to facilitate the identification and location of patients and their contacts.

The European Public Health Committee of the Council of Europe published a document 'Sexually Transmitted Diseases (STD)-Scope and Control Measures' comprising a report (Council of Europe, 1974) and various appendices, which include a Resolution (adopted by the Committee of Ministers), the principles and practices necessary for promoting progress in the control of STD in member states; and model reporting forms. Later in the year the World Health Organization, in collaboration with the International Union Against Venereal Disease and Treponematoses, arranged a meeting on the subject of 'Health Education in the Control of STD'; participants with an interest in this field, including six doctors from Britain, came from all regions of the world.

\section{References}

Department of Health and Social Security (1974) 'Special Treatment Clinic: a Design Guide'. Department of Health and Social Security, London

COUNCIL OF EUROPE (1974) 'Sexually Transmitted Diseases (STD), Scope and Control Measures; report by T. Guthe, Council of Europe, Strasbourg 